\title{
Naïve Realism, Hallucination, and Causation: A New Response to the Screening Off Problem
}

\author{
Alex Moran \\ Queens' College, University of Cambridge \\ Penultimate draft \\ (Final draft published in the Australasian Journal of Philosophy)
}

\begin{abstract}
This paper sets out a novel response to the 'screening off' problem for naïve realism. The aim is to resist the claim (which many naïve realists accept) that the kind of experience involved in hallucinating also occurs during perception, by arguing that there are causal constraints that must be met if an hallucinatory experience is to occur that are never met in perceptual cases. Notably, given this response, it turns out that, contra current orthodoxy, naïve realists need not adopt any particular view about the psychological nature of hallucinatory experience to handle the screening off problem. Consequently, room opens up for naïve realists to endorse whatever theory of hallucinatory experience seems to best capture the distinctive nature of such episodes.
\end{abstract}

Keywords: Naïve Realism, Disjunctivism, Screening Off, Causal Theory of Perception, Perception, Hallucination.

... after the relevant changes have occurred in the relevant structures... one visually perceives a flash of light or has the illusion of doing so, according to the character of the initial stimulus.

- J. M. Hinton [1973: 75]

\section{Introduction}

Naïve realism is a theory about perceptual experience, i.e. the kind of experience involved in genuine perception. Its first claim is that perceptual experiences are complex, relational events consisting in the presentation to subjects of external objects and qualities. Its second is that perceptual experiences have their distinctive conscious characters in virtue of presenting the external objects and qualities they do. As Martin (I997: 83) writes, 'according to naïve realism, the 'actual objects of perception, the external things such as trees, tables, and rainbows...partly constitute one's perceptual experience, and hence determine the phenomenal character of one's perceptual experience'.

Naïve realism is thus a disjunctivist view since it does not apply to hallucinatory experience-that is, the kind of experience involved in hallucination. ${ }^{\mathrm{I}}$ For such experiences do not consist in the presentation of external objects. Naïve realists must therefore recognise a further kind of experience-hallucinatory experience-that does not consist in the presentation of external things (see Snowdon 2005a: I36-7).

As for the nature of hallucinatory experience, naïve realists have no official view. However, to have a total view of sense-experience they must say something regarding the nature of these episodes (cf. Dancy 1995; Sturgeon 1998). Moreover, there is reason for naïve realists to want such a theory. For rival 'common factor' views have one, and would therefore appear to have an advantage over naïve realists who say nothing

\footnotetext{
${ }^{\text {I }}$ Whether it applies to illusory experience is a delicate question we can set aside.
} 
about the nature of hallucinatory experience. (For more on disjunctivism vs. common factor views see Martin 2004; Crane 2006; Pautz 2010.)

An important question, then, concerns what naïve realists should say regarding hallucinatory experience. I have views here, and sketch them briefly later $\left(\$_{4}\right)$. However, this paper is primarily concerned with another issue, namely, the so-called 'screening off problem', which threatens the second core claim of naïve realism: that the perceived external objects and their qualities ground perceptual phenomenal character. For it is widely held that this problem, even if not fatal to naïve realism, places severe restrictions on what naïve realists can say about hallucinatory experience. Indeed, it has been argued by Martin (2004, 2006), the originator of the screening off problem, that naïve realists can only give a 'negative' account of hallucination in purely epistemic terms. Yet many find this account inadequate, myself included (see esp. \$3.2, cf. also Siegel 2004, 2008; Farkas 2006; Hawthorne \& Kovakovich 2006; Byrne \& Logue 2008; Smith 2008; Sturgeon 2008; and Pautz 201 I). Moreover, there are reasons to think it problematic that naïve realists are constrained in terms of what they can say regarding the nature of hallucinatory experience (cf. $\$ 4)$.

Fortunately, there's a way out. For in this paper, I will argue that naïve realists can solve the screening off problem without adopting any theory of hallucinatory experience in particular, and are therefore free to adopt whatever theory of hallucinatory experience best captures the distinctive natures of such episodes. Indeed, if I am right, naïve realists can even offer a 'positive' account of such experience of the sort that I prefer.

Roadmap. The following section sets out the screening off problem $(\$ 2)$. The next section sets out my proposed response, before briefly criticising the main extant replies $\left(\$_{3}\right)$. The final section then concludes, by setting out some advantages my view has over alternative responses $(\$ 4)$.

\section{Screening Off}

The screening off problem targets the second core naïve realist thesis concerning the phenomenology of perceptual experience. We can represent the problem as an argument with two main premises:

(I) In cases of perception, one has an experience of the hallucinatory kind.

(2) If, in cases of perception, one has an experience of the hallucinatory kind, then naïve realism is false.

$\therefore \quad$ Naïve realism is false.

The argument is valid, so naïve realists must resist one of the premises. Many reject (2) and accept (I), but I shall advocate doing the opposite. But let us first consider, in the following two sub-sections respectively, the motivations for the two main premises. 


\section{I Premise (I)}

The argument for (I) turns on two claims. The first is that to have an experience of the hallucinatory type, it is sufficient to be in the right kind of antecedent brain state. ${ }^{2}$ The core idea is that hallucinatory experiences are 'inner events', so that causing hallucinatory experiences only requires inducing the right local condition. As Martin (2004: 59) writes, we tend to conceive of hallucinations as 'inner experiences', and so 'have the conception that the occurrence of such events imposes no additional condition on the world beyond the subject's putative state of awareness'.

Compare: naïve realists claim that perceptual experiences-experiences of that distinctive type-constitutively involve external objects, meaning that the occurrence of a mere brain state is insufficient for such experiences to occur. However, while naïve realists might be right that perceptual experiences constitutively depend on external objects, it seems clear that hallucinatory ones do not so depend. But this suggests that the occurrence of a brain state should be sufficient for an hallucinatory experience to occur. The following principle captures this idea:

\section{Local Supervenience}

If a subject, $\mathrm{X}$, is caused to have an hallucinatory experience by some brain state, $\mathrm{B}$, then if any subject, $\mathrm{Y}$, is in the same brain state as $\mathrm{X}$, that brain state will cause Y to have an hallucinatory experience also. ${ }^{3}$

The second claim that the argument for (I) depends on is the plausible one that for each perceiver $\mathrm{X}$, there is a possible hallucinator, $\mathrm{Y}$, whereby the brain state causing X's perceptual experience is the same kind as the one causing Y's hallucinatory experience. If, for example, you're now perceiving a red apple, and if the brain state causing your experience were artificially produced elsewhere, it's plausible to think it would produce an hallucinatory experience subjectively just like your own. Compare Foster (I986: I84), who notes that 'given any genuine visual perception...we can envisage a situation in which...by electrically stimulating the optic nerves...the subject would have a visual hallucination which was, as an experience, exactly like it'.

Importantly, the claim here is only that if some brain state causes an experience of the perceptual kind, it could also cause an experience of the hallucinatory kind. So no questions are begged against the naïve realist. For the above is consistent with the disjunctivist thesis, which all naïve realist's have to endorse, that perceptual and hallucinatory experiences have different natures, since perceptual experiences consist in external objects being presented whilst hallucinatory experiences don't. (We might call this 'minimal disjunctivism', given the more radical views 'disjunctivism' sometimes denotes in the literature.)

Now, if for each perceiver, $\mathrm{X}$, there is a possible hallucinator, $\mathrm{Y}$, such that the brain state causing X's perceptual experience is (type-)identical with the brain state causing

\footnotetext{
${ }^{2}$ I assume here that the role of the brain (on a naïve realist view) is to act as the antecedent cause of an experience, rather than to partially constitute it. Others prefer the latter view, see e.g. Johnston (2004) and Snowdon (2005b), I have argued against it elsewhere, see Moran (forthcoming-a). (The part-constitution view doesn't solve the screening off problem in any case, see Martin I992: I 86-7.)

${ }^{3}$ N.b. X and Y could well be the same subject in possible situations, as well as different subjects.
} 
Y's hallucinatory experience, then given Local Supervenience, (I) holds. For it follows that whenever someone has a perceptual experience, the brain state proximally causing that experience also causes an hallucinatory experience, so that whenever one has a perceptual experience, one also has an hallucinatory experience.

\subsection{Premise (2)}

If (I) is true, one can hold either that (in cases of perception) the subject has two experiences each of different kinds, or else just one experience instantiating two different kinds (see Johnston 2004; Martin 2004; Snowdon 2005b). And plausibly, the second view is the correct one here. As Snowdon (2005b: 303) writes it is hard to understand the possibility of, say, simultaneously undergoing one experience that is a hallucination as of a pink elephant... and also another perceptual experience of a pink elephant...[For] as total experiences they seem to compete' (cf. Martin 2004: 59).

Suppose, then, that in each case of perception, there is just one experience had by the subject, instantiating both the hallucinatory and the perceptual kind. This makes trouble for naïve realism, for presumably, we can explain why this experience has its character just in terms of the properties it has in virtue of falling under the hallucinatory kind, thus leaving no reason to bring in the properties it has in virtue of instantiating the perceptual kind (cf. Martin 2004, 2006; Nudds 2013; French 2015; Soteriou: 20I6). However, this seemingly implies that the presentational elements of experience are 'redundant to the explanation of [its] phenomenal aspects' (Martin 2004: 59). In short, there seems to be no need to appeal to the external items our experiences present in order to explain why they have the characters that they do, for we can explain this just by appealing to the properties they exemplify because of instantiating the hallucinatory kind. ${ }^{4}$ So the second core claim of naïve realism is false, as is naïve realism itself. $^{5}$

One might reply that both the properties the experience has because it instantiates the hallucinatory kind and those it has because it instantiates the perceptual kind explain its character. However, this would simply lead to a worry regarding overdetermination (cf. Martin 1992: 177-8; Fish 2009: 98). For if the properties the experience has due to instantiating the hallucinatory kind are sufficient to explain its character, then bringing in further properties would generate massive overdetermination. Yet that result looks clearly problematic. ${ }^{6}$

(Imagine, for example, that because it instantiates the hallucinatory kind, the experience presents certain sense data. Surely then there would then be no need to appeal to the external objects and qualities the naïve realist says the experience presents in or-

\footnotetext{
${ }^{4}$ Claiming instead that one has two experiences of different kinds whenever one perceives rather than just one experience of two kinds doesn't help. For then we face the question: why not just explain why I am having an experience with this character in terms of the presence of the hallucinatory experience? Why bring in a further type of experience, conceived on naïve realist lines? (Cf. Fish 2010: 48).

${ }^{5}$ Byrne \& Logue (2008: 87) suggest naïve realists could respond here by giving up their central claim about phenomenology. The resulting view, however, would not really be in the spirit of naïve realism, at least as it is standardly conceived. This is well brought out by Martin (2004: 64).

${ }^{6}$ Pautz (manuscript) claims otherwise, arguing that accepting systemic, widespread constitutive overdetermination is a viable option (for 'disjunctive intentionalists'). I disagree. (We know widespread causal overdetermination is problematic. But this point easily extends to the constitutive case as well.)
} 
der to explain its character. And if one did appeal to these naïve realist properties, one would end up with widespread overdetermination of perceptual phenomenology.)

This, then, is the motivation for (2): if ( $\mathrm{I}$ ) holds, then, apparently, the naïve realist's claim about why our perceptual experiences have their distinctive characters is either explanatorily redundant or else leads to massive and systemic overdetermination. But neither result is acceptable, and so if (I) is true naïve realism is false.

\section{Causal Conditions}

In this section, I first set out my proposed solution to the screening off problem $\left(\$_{3 . I}\right)$. I then criticise some naïve realist responses to it $\left(\$_{3.2}\right)$. This will help explain later why my view is preferable.

\section{I The Proposed View}

I propose to incorporate elements of the 'causal theory of perception' within a naïve realist framework. In this way, we can solve the screening off problem by rejecting:

(I) In cases of perception, one has an experience of the hallucinatory kind.

Rather than:

(2) If, in cases of perception, one has an experience of the hallucinatory kind, then naïve realism is false.

On the proposed view, it is never so that one has the distinctive kind of experience involved in in hallucination in cases of genuine perception. So it is (I) that's false, not (2). And this looks like the right result: after all, the case for (2) is compelling.

In more detail, the view is this. Premise (I) depends upon Local Supervenience: the claim that hallucinatory experiences occur whenever the right kind of brain state is produced. Again, the motivation here is that hallucinatory experiences are inner events', which occur whenever the subject is in the right intrinsic state. In my view, naïve realists can reject this assumption, by claiming that (i) hallucinatory experiences are essentially (and so necessarily) caused in a certain way, so that no hallucinatory experience could occur in the absence of the right causal conditions, and that (ii) these causal conditions cannot be met in perceptual cases. For this entails that in perceptual cases, it is impossible for hallucinatory experiences to occur. But then Local Supervenience and (I) are false, and the screening off argument fails.

The standard causal theory of perception in fact presupposes a common factor view of sense-experience. ${ }^{7}$ On this view, there is just one basic kind of experience, common to perception and hallucination. Accordingly, proponents of this view must explain why certain instances of this experience-type are perceptual rather than hallu-

\footnotetext{
7 This view was first propounded by Grice (196I), subsequently developed subsequently by Pears (1976), Strawson (1979), Lewis (I980) and others.
} 
cinatory. The answer often given is that instances of this experience-type are perceptual iff they are caused in a standard (non-deviant) way.

One way to see the plausibility of this view is to consider cases of 'veridical hallucination': cases wherein someone has an hallucinatory experience as of an F, whilst in the presence of a genuine F. For instance, I might be standing before a clock while having an hallucinatory experience as of a clock (see Grice 196I). Yet whilst my senseexperience is fully 'accurate'-for how things seem to be matches up with how things are-nevertheless, my experience is hallucinatory rather than perceptual. However, if one can have an hallucinatory experience as of a clock whilst in the presence of a genuine clock, then having an experience as of a clock in the presence of one is not sufficient for perceiving it. But why is that exactly? A plausible answer is that in order to perceive the clock, it has to be causally responsible for the experience in the right way. When the clock is causally responsible in this way, then one perceives it. Otherwise, one just hallucinates. As for when we have the right kind of causation, the answer is: when there's causation of the standard kind. ${ }^{8}$

It is of course notoriously difficult to define 'standard' and 'deviant' causation. However, it doesn't follow that these notions are irremediably obscure. Rather, we seem easily able to judge whether a case involves standard or deviant causation. Indeed, our understanding of these notions is arguably a crucial part of our intuitive grasp on the distinction between perceptual and hallucinatory experience itself. ${ }^{9}$

With that in mind, what I suggest is that whilst the idea that perceptual experiences only occur as a result of standard causation is typically put forward by common factor theorists, there is nevertheless room for naïve realists to adopt an analogous view. After all, it seems extremely plausible, regardless of one's views elsewhere, to think that perception is at least partially causal in character. For perceiving seems to be a matter of being in contact with the world in a distinctive kind of way, and it seems very plausible to think that (at least part of) what it takes to be in contact with the world in that way is for the relevant parts of the world to have a distinctive sort of causal impact upon one (cf. Child: 1994).

Notice, however, that in accepting that there are causal constraints on perceptual experience, naïve realists acquire a rather different view to common factor theorists. For, given their theory of experience, common factor theorists don't have to say that the type of causation involved makes any difference to the kind of experience produced. Rather, on their view, we have just one basic experience-type, whose mental nature is invariant across perceptual and hallucinatory cases. Instances of this experience-type are then either perceptual or hallucinatory depending on their aetiology. By contrast, in accepting that there are causal conditions on perceiving, naïve realists adopt a view on which the kind of causation in play makes a crucial difference to the basic kind of experience produced - not just to whether a certain experience-type has a certain property (being a perception/being an hallucination) as on the standard causal theory. Specifically, naïve realists end up holding that perceptual experiences (that is,

\footnotetext{
${ }^{8}$ It is not enough just to say that an instance of the common experience-type is perceptual when it is caused by the clock. For one might have a veridical hallucination whereby the clock causes the experience in a deviant manner (cf. Lewis I980). Hence the need to bring in standard causation.

${ }^{9}$ Cf. Child (I994: I 42): 'The point of bringing out the causal difference between vision and hallucination is not to allow us to distinguish states of affairs that were indistinguishable before. Rather, it is to yield a philosophical understanding of the distinction'.
} 
experiences of that distinctive type) can occur only if there is causation of the appropriate sort, involving the relevant external item(s) in the standard way. ${ }^{\text {Io }}$

This, however, is no objection to the position combining naïve realism with the idea that perceptual experiences essentially (and so necessarily) require causation of the standard sort. Rather, we can simply read the above as clarifying how the naïve realist version of the view differs from the standard causal theory, which presupposes a common factor view. I suggest, therefore, that while the causal theory is standardly adopted by common factor theorists, there is room for naïve realists to accept a version of this view. On that view, an experience of the perceptual kind occurs only if there is standard causation connecting the subject in the right way to the external items sensed. ${ }^{\text {II }}$

One reason naïve realists might want to accept this modified causal theory is that it provides a compelling way to resist an important argument against their view: the causal argument (for presentations of this argument see Robinson I994; Foster 2000; Smith 2002; Crane 2005; Snowdon 2005b). Driving this argument is the idea that the same kind of proximate cause always produces the same type of immediate effect. Consider, for instance, a case of perception and a corresponding case of (total) hallucination. And suppose the perceptual experience has the same proximate cause as the hallucinatory one. It then follows, by the same cause, same effect principle, that even in the hallucinatory case, the brain state causes an experience of the perceptual kind. But this is unacceptable for naïve realists, for they hold that perceptual experiences consist in the presentation of external items while hallucinatory experiences do not.

It is sometimes said that naïve realists can respond here by rejecting the same cause, same effect principle, on the grounds that perceptual experiences (at least according to naïve realism) have external objects as constituents (see Martin 2004: 55; Nudds 20 I3: $274-5$ ). The thought is that since the mere occurrence of a brain state is insufficient for an external object of perception to exist, it follows that no brain state is sufficient for the occurrence of a perceptual experience, contrary to what the 'same cause, same effect' principle implies.

However, this response faces a problem regarding cases of veridical hallucination. For, in cases of veridical hallucination, an appropriate external object of perception exists, so that there's no reason why the relevant brain state shouldn't produce a perceptual experience. Yet we still do not want to say that the subject has an experience of the perceptual kind in these situations. For cases of (total) hallucination, even if they are 'veridical', never involve the presentation of external items. ${ }^{\text {I2 }}$

\footnotetext{
${ }^{\text {Io }}$ Against this, one might say that it's implausible to think the aetiology of a brain state could make a difference to the kind of effect it will produce (see Robinson I994: I 54; Foster 2000: 28; Johnston 2004: I I6; and Snowdon 2005b: 292). However, whilst this is an important objection, I lack the space to deal with it here. (I do, however, take it up elsewhere (see Moran manuscript-a).

II This view is not incompatible with the 'anti-causalist' position developed in Snowdon (I98I) (as Snowdon himself agrees, [personal communication]). For, what Snowdon argues is just that the causal theory is mistaken as a piece of conceptual analysis. But that is surely compatible with it being part of the essence of such experiences that they be caused in a certain manner. The only way to deny this is to maintain that our concept of a thing necessarily coincides with its essence, but that is surely false. (Recall Locke's distinction between nominal and real essence!)

${ }^{12}$ Notably, this kind of consideration also undermines a recent suggestion from Allen (20 I 5: 29930I) regarding rejecting premise ( $\mathrm{I}$ ). The idea is that (at least with Allen's view about hallucination in the background, viz. that such experiences are essentially a type of imaginative episode), naïve realists can maintain that experiences of the hallucinatory kind cannot occur in cases of perception, since an
} 
If, however, naïve realists maintain that there are causal conditions on having a perceptual experience (as I have suggested), they can explain why the relevant brain state doesn't cause a perceptual experience in the case of veridical hallucination. For they can say that since it lies in the nature of perceptual experiences to occur only when there is standard causation, experiences of this kind cannot occur in cases of hallucination, veridical or otherwise-for in such cases, we have non-standard, causation, so the brain state doesn't cause a perceptual experience (cf. Foster 2000: 40-4I). Thus, by adopting elements of the causal theory of perception, naïve realists can provide a compelling response to an important problem for their view. ${ }^{13}$

At this point, I want to claim that naïve realists can use this same basic strategy to handle the screening off argument. For what naïve realists can claim is that, just as there are causal constraints on perceptual experiences occurring, so too there are causal constraints on hallucinatory experiences occurring-since it lies in the nature of such episodes to be caused in a non-standard or deviant manner. Let us refer to this as 'the argument from analogy'. The core idea is that just as naïve realists can say that there are causal conditions on perceptual experience (and thus reply to the causal argument) so too they can say that there are causal conditions on hallucinatory experience (and thus rebut the screening off argument).

This core idea here-that there are causal conditions on hallucinating-was in fact suggested by C. D. Broad (I962: 190-I):

\begin{abstract}
We may define the term 'hallucination'... as follows. We shall say that a person was having such an experience on a given occasion, if and only if the following two conditions were fulfilled. (i) He was ostensibly seeing, hearing, touching, or otherwise sensibly perceiving a certain thing or person or event or state of affairs, as external to his body. Whilst (ii) at that time his eyes, ears, fingers, or other receptor sense-organs were not being affected in the normal physical manner...by any such thing, person, event, or state of affairs as he was ostensibly perceiving.
\end{abstract}

According to Broad, it's no contingent matter that hallucinations occur as a result of non-standard causation. Rather, it is an essential and so necessary condition on something being an hallucination that it be caused in this way.

I submit that this view is rather intuitive. It seems natural to think that if an experience is hallucinatory, it must have been non-standardly produced. Indeed, one might well think that this is just part of what it is for an experience to be hallucinatory. For aren't hallucinatory experiences precisely what you get 'when things go wrong', in a distinctive kind of way? Indeed as Thau (2004: 250) writes, it's very plausible to conceive cases of visual hallucination as precisely as cases of 'failure[s] to see' (cf. Johnston

essential condition on an hallucinatory experience occurring is that a suitable object of perception be absent from the scene before the eyes of the relevant subject (cf. also Martin 2004: 58). The thought is then that since this condition is never met in perceptual cases, it follows that in genuinely perceptual cases hallucinatory experiences never occur. (Obviously if I perceive a clock, then the condition that a clock be absent from the scene before the eyes is not met.) But this implies that (I) is false.

The trouble here is that the absence of the appropriate external object is not in fact necessary for the occurrence of an hallucinatory experience. For one could well have an hallucinatory experience as of a clock even when there is a clock out in the scene before the eyes-as cases of veridical hallucination show.

${ }^{13}$ Note also that this view provides the naïve realist with a good answer to the following question: when is an object a constituent of a perceptual experience, as opposed to merely a cause of a veridical hallucination lacking that object as a constituent? For surely this question demands an answer. And my answer would be: $\mathrm{x}$ is a constituent of perceptual experience e whenever $\mathrm{x}$ causes $\mathrm{e}$ in the standard way. 
2004: I35, Thau 2004: 250, and Tye 2014: 303). But is it not natural, also, to cash out that distinctive kind of way in causal terms? The point, however, if it lies in the essence of hallucinatory experiences to be caused in a certain manner, then they are caused in that manner whenever they occur. ${ }^{\mathrm{I}}$

The idea that deviant causation is an essential condition for the occurrence of an hallucinatory experience is also part of the causal theory of perception. Again, common factor theorists maintain that there is just one basic experience-type common to cases of perception and hallucination, so whilst needing to explain why some instances of this experience-type are perceptual, they must also explain why some instances of this experience-type are hallucinatory. The standard answer, once again, appeals to causation. The view is that a given token of the common experience-type is hallucinatory iff it is caused in a non-standard or deviant way.

In my view, naïve realists can also make this kind of claim. That is, they can also maintain there are causal constraints on the occurrence of both perceptual and hallucinatory experience. Of course, naïve realists will deny that there is just one basic experience-type, whose instances are perceptual when caused in one manner and hallucinatory when caused in another. However, they can accept the following view. There are two basic kinds of experience: perceptual and hallucinatory, which differ in nature (at least in the way that is implied by 'minimal disjunctivism'). Moreover, it lies in the nature of the first experience-type (distinctive of perceptual cases) to be generated by a process involving appropriate causation by the perceived external item(s). Yet when it comes to the second experience-type (distinctive of hallucinatory cases), it lies in their nature to be generated by deviant or non-standard causation. And so it never happens that we have a perceptual experience and an hallucinatory one at once. ${ }^{15}$ (I rely here on the idea that no causal chain can be both standard and non-standard: being standard and being non-standard are incompatible properties of causal chains.)

Against this, it might be said that whilst it's plausible to think that there are causal conditions on hallucinating, it's less plausible to think the same of having the kind of experience involved in hallucinating. However, once we allow naïve realists to say that there are causal constraints on having a perceptual experience (as surely we must), it is unclear how we could bar them from claiming that there are causal conditions on having an experience of the hallucinatory type. (And anyway: why think that the same causal conditions on hallucinating don't apply to hallucinatory experience proper?) Accordingly, it appears naïve realists can respond to this objection.

\footnotetext{
${ }^{\text {I4 }}$ An interesting objection here turns on the thought that it's at least metaphysically possible to have an uncaused hallucination. For if that's so, then plausibly, it can't be true that hallucinatory experiences are essentially deviantly caused. In reply to this, I suggest we hold that the limit case of deviant causation is the case wherein causation is entirely absent. For then, we can allow for the possibility of uncaused hallucinatory experience, whilst accepting that deviant causation is essential for such an experience to occur. On this view, when there's no causation at all (but not causation by an absence) we have deviant causation, for deviant causation just is what you get when don't have standard causation.

${ }^{15}$ Views that also imply that perceptual experiences and hallucinatory experiences never co-occur, are recommended to naïve realists by Hinton (I973: 75); Foster (2000: 4I); and Snowdon (2005b: $303)$, in related contexts. However, these authors do not set out their proposals in any real detail, and none are concerned with the screening off problem as I am.
} 
The suggestion, then, is that naïve realists can claim that there are causal conditions on both perceptual experience and hallucinatory experience. Moreover, I say that in so doing, they can offer a compelling response to the screening off argument. ${ }^{16,17}$

This view, of course, implies that Local Supervenience is false. Again, this principle was meant to follow from the idea that hallucinatory experiences are 'inner events', which 'demand nothing of the external world' in order to occur. However, if there are causal conditions on the occurrence of both perceptual and hallucinatory experience as I have claimed, then it is just not true that having an hallucinatory experience is just a local matter in this way. For, on the contrary, there are conditions that go beyond the intrinsic or local state of the subject that have to be met if an hallucinatory experience is to occur. Consequently, both Local Supervenience and (I) are false, and the screening off argument fails. ${ }^{\mathrm{I}}$

Accordingly, if there are causal conditions on the occurrence of both perceptual and hallucinatory experience as I have claimed, then it's impossible for hallucinatory experiences to occur in cases of perception, regardless of the kind of brain state the subject is in. For if the subject is having a perceptual experience, there must have been causation of the standard sort. However, this kind of causation excludes causation of the deviant or non-standard kind being present. Yet without deviant causation, it is

${ }^{16}$ I have said that it lies in the essence of perceptual and hallucinatory experiences to be caused in certain ways. But one could plausibly think there are possible worlds where these experiences occur and yet are not caused in these ways. Now I am not sure that I accept the reality of such possible worlds. However, if I were forced to do so, I would have to settle for a weaker claim, viz. that in the actual world, perceptual and hallucinatory experiences are always caused in the standard/deviant manner, even if in other worlds they are generated in other ways. (However, there is reason to want to hold on to the stronger claim: for given this claim about essence, we can say that such experiences are necessarily caused in the ways they are without this necessity claim simply being brute and inexplicable. See fn. 26 in $\$_{4}$ ).

${ }^{17}$ Here is another worry. Suppose the role of the brain states involved in perceiving/hallucinating is to constitute or ground those experiences rather than cause them. Presumably, the brain states would then classify as full grounds for the relevant experiences in the hallucinatory cases. So it would follow that when I have an hallucinatory experience E, which, say, consists the presentation of certain sense data, I have E (fully) in virtue of being in brain state B. But plausibly, there could be some possible world wherein being in brain state $\mathrm{B}$ involves having $\mathrm{E}^{*}$, i.e. an experience with a different nature to $\mathrm{E}$ (say that $\mathrm{E}^{*}$ involves representing a proposition, rather than presenting sense data). But if that is so, then a plausible necessitation requirement on grounding - which would entail that if B (fully) grounds E then necessarily if B occurs then B grounds $E$ (so that necessarily if B occurs then E occurs)-will imply that whenever I am in brain state B, I have two distinct hallucinatory-experience-types, $\mathrm{E}$ and $\mathrm{E}^{*}$. But then we end up with problematic overdetermination, of just the sort we worried about in $\left(\$_{2}\right)$.

In reply I say the following. First, I have reason to think that the role of the brain is to cause rather than constitute or ground our sensory experiences (cf. fn. 2). Second, it is unclear whether we should allow that $\mathrm{B}$ is able to ground one experience-type in one possible world and another experience-type in another possible world. For if B grounds $\mathrm{E}$ in w, then arguably it lies in the nature of $\mathrm{B}$ to ground $\mathrm{E}$ (and only E) in all possible worlds. Indeed, one arguably needs this kind of essence claim to underwrite the relevant necessitation principle the present objection requires (cf. Audi 20 I2). (We should of course allow a single experience-type to grounded in various different ways. What I am querying is whether we should allow a single brain state to be able to ground different experience-types in different worlds.) Lastly, I deny the relevant necessitation principle the argument requires, see my forthcoming-b; see also my manuscript-a for a fuller account of how denying this principle blocks the objection.

${ }^{18}$ There may of course still be a sense in which hallucinatory experiences are 'inner events', since they are still plausibly viewed as being events that occur 'within' the subject, and which do not, say, involve external objects as constituents. The mistake that people have been making, perhaps, in using the 'inner' nature of these events to argue for Local Supervenience, is that of assuming that no 'inner experience' could have extrinsic requirements on its instantiation. (Thanks to Ralf Bader here.) 
impossible for an hallucinatory experience to occur. ${ }^{19}$ The upshot is that in accepting a modified version of the causal theory in the way I have suggested, the naïve realist can handle the screening off argument, by claiming premise (I) is false. (As we will see, this move has various advantages, cf. $\$ 4){ }^{20}$

This, then, is my proposed response to the screening off problem. The core idea is that, contra what many naïve realists accept, one cannot in fact have an experience of the hallucinatory kind in perceptual cases. This view might be called 'restrictive disjunctivism', since it prohibits hallucinatory experiences from occurring in cases of genuine perception. Likewise, it prohibits experiences of the perceptual kind from occurring in cases of hallucination, which, as we have seen, is a result the naïve realist needs as well (recall the discussion of the causal argument earlier in this section). ${ }^{2 \mathrm{I}}$

\subsection{Extant Replies}

The screening off argument depends on two premises. Above, I advocated rejecting premise (I). Yet many naïve realist advocate rejecting premise (2) whilst accepting (I). The core idea is that by adopting certain views of hallucinatory experience, we can accept premise (I) - that whenever one has a perceptual experience, one has an hallucinatory experience also-whilst rejecting premise (2), which says that if (I) holds then naïve realism is false.

Martin (2004, 2006, 2013) advocates this approach. But there are problems. ${ }^{22}$ One is that it just looks unintuitive to claim that even in cases of perception one has an experience of the hallucinatory kind, so that in cases of perception two experiencetypes are instantiated at once (however this is interpreted). But further, there is the deeper worry (which Martin himself acknowledges) that this strategy places 'severe

\footnotetext{
${ }^{19}$ Presumably, standard and deviant causation alike are vague notions. However, if that is so, then it appears we can easily generate cases wherein it's vague whether one is having a perceptual experience or an hallucinatory experience. Yet this seems to put 'vagueness in reality', rather then merely 'in our representation of it'. And that might seem unacceptable. My response here is twofold. First, I am convinced that the notion of vagueness in reality is coherent (see van Inwagen 1990, and, in addition, that all of us might have to accept that there is 'vagueness in reality' in any case (see Merricks 200I). Second, I am in fact unsure that we cannot handle the relevant vagueness in the standard ways, which don't involve positing 'vagueness in reality'. But that clearly is a question to be addressed elsewhere.

${ }^{20}$ It should be reiterated that my strategy here has been to borrow elements of the causal theory of perception, which arguably all rival (common factor) theories to naïve realism require, in order to solve the screening off problem. The key idea is that since e.g. the causal theorist can maintain that perceptual and hallucinatory experiences have causal conditions on their occurrence, so too can the naïve realistalbeit in her own way. Accordingly, whilst my claim that hallucinatory experiences cannot occur in cases of perception (since they must be caused in a deviant manner) may seem tailor-made to solve the screening off problem, it is by no means ad hoc. Rather, follows from the plausible idea, central to this paper, that naïve realists can employ elements of the causal theory albeit within their own framework.

${ }^{2 \mathrm{I}}$ N.b. whilst the present proposal implies that Local Supervenience fails, it is not inconsistent with the local supervenience of sensory experience in general. On the present view, subjects in the same brain state might differ in terms of what kind of experience they have. But they cannot differ in terms of whether they are having an experience at all. Indeed, sameness of brain state guarantees sameness of phenomenology: all that differs depending on the causal context is the type of experience the subject has. (Contrast Fish 2009 whose view does imply that sense-experience doesn't locally supervene.)

${ }^{22}$ Other advocates of Martin's view include Soteriou (2005) and Nudds (2013). For discussion of how exactly Martin's view of hallucinatory experience is meant to solve the screening off problem see Byrne \& Logue (2008); Hellie (2013); Nudds (2013); Soteriou (2016); and Moran (manuscript-c).
} 
constraints on what can be said about the nature of [hallucinatory experience]' (Martin 2004: 54). Indeed, it seems that in order to pursue this reply, one has to endorse one or another radical claim about the mental nature of hallucinatory experiences. But this is arguably an unacceptable price to pay.

For instance, Martin claims that there is nothing more to undergoing an hallucinatory experience than being in a state that cannot be told apart by reflection from having the corresponding perceptual experience. However, it is hard to see how an hallucinatory experience could merely be a 'negative epistemic state' in this manner. Moreover, other philosophers have followed Martin in rejecting (I), and have also ended up with radical views of hallucinatory experience, namely Fish (2009) and Hellie (2013). On Fish's view, for example, $e$ is an hallucinatory experience iff it has all and only those cognitive effects that a corresponding perceptual experience would have were it to occur in a rational subject. Fish also claims that if something is an hallucinatory experience, then unlike perceptual experiences, it lacks the kind of phenomenal character that sensory experiences typically have. (This radical claim is endorsed by Sturgeon 2008 and Logue 20I3a.) Whereas on Hellie's view, hallucinatory experiences form a heterogeneous class of mental events with various psychological natures. Thus, nothing guarantees that this hallucinatory experience will have the same psychological nature as that experience, ....etc. ${ }^{23}$

Now each of these views is clearly radical in various ways. Moreover, each seems rather implausible. For, just as it's hard to see how an hallucinatory experience could be a mere negative epistemic state, so too it's hard to believe that such experiences are events lacking in phenomenal character defined only by their characteristic causal upshots, or that they fail to share a common psychological nature. Accordingly, we should be dissatisfied with all of these answers to the screening off problem.

Accordingly, I claim that my view is to be preferred to the main rival answers to the screening off problem. For on my view, naïve realists do not have to make any radical claims about the nature of hallucinatory experience. Indeed, they can remain silent about the mental nature of hallucinatory experience, and still resist the screening off problem. (For further advantages of my view see $\$ 4$.)

\footnotetext{
${ }^{23}$ Logue (2013b) has also argued that naïve realists can handle the screening off argument without adopting Martin's view of hallucinatory experience. However, it is unclear whether the version of naïve realism Logue is concerned with is the version of naïve realism I am interested in here. For according to my version of naïve realism, the external objects of perception and their qualities determine perceptual phenomenal character. Yet on the view that Logue proposes, it is the representational properties of our experiences that determine their phenomenal characters. True, Logue also holds that our experiences have their representational properties in virtue of being relations to mind-independent objects, and according to her this makes her position classify as a form of naïve realism. However, it is unclear to me whether contemporary naïve realists - who typically deny we should think of experience in representational terms - would be willing to accept this idea. (Logue is in fact quite clear that she is not primarily concerned with the version of naïve realism I am interested in, on which it is external objects and qualities that constitutively determine phenomenal character, see Logue (2013b: fn. 5). Indeed, the view she recommends in her paper is closer to the 'relational' form of intentionalism defended by Schellenberg (201 I) and McDowell (2013) than the form of naïve realism I'm concerned with here.)
} 
This paper has developed a novel response to the screening off problem, which challenges premise (I) of the argument rather than (2), and thus rejects the unintuitive claim that in cases of perception, we have experiences of both the perceptual and the hallucinatory kind. I now conclude by noting some advantages of this proposal.

One advantage is that this proposal does not force naïve realists to say anything regarding the psychological nature of hallucinatory experience. A related advantage is that naïve realists are then able to put forward whatever theory of hallucinatory experience best captures the distinctive natures of these episodes. In my view, this will have to be a 'positive' view of hallucination, on which, in particular, hallucinatory experiences consist in mind-dependent items being presented to the subject [Moran manuscript-a]. I have defended this view elsewhere, and so won't go into detail here. ${ }^{24}, 25$ One ought to note, however, that this last demonstrates a third advantage of my proposal, namely, that naïve realists are left free to put forward a 'positive' view of hallucination, the screening off problem notwithstanding. This is important since many opponents of naïve realism, following maintain that a positive view of hallucination is required, and yet see naïve realism as unable to provide one, precisely due to the screening off problem.

This last bears on the more general debate about perceptual experience, which currently is primarily between intentionalists and naïve realists (cf. Crane: 2006). For, one of the main criticisms intentionalists have levelled at naïve realists is that the latter can offer no satisfactory account of hallucination-the assumption being that naive realists will have to make some radical or unintuitive claim about such episodes in order to handle the screening off problem (see Burge 2005; Pautz 20 I I and esp. Searle 20I5). My point is that if this assumption is misguided, as I have claimed-that is, if naïve realists can handle the screening off problem whilst remaining neutral about the mental nature of hallucinatory experience - then this line of criticism fails.

Lastly, by adopting my proposal, naïve realists can deal with an important criticism from Johnston (2004: I27), who claims naïve realists are guilty of employing a 'backwards methodology' when it comes to hallucinatory experience, since their views here typically arise 'as an attempt to answer [an] argument', rather than 'from an investigation of the distinctive features of hallucination itself. The point is that, even if this complaint is valid against some naïve realists, it has no force against naïve realists who adopt the present proposal. For that proposal enables one to handle the screening off

\footnotetext{
${ }^{24}$ The idea that whilst naive realism is true of perceptual cases, a sense datum view is true of the hallucinatory ones is briefly suggested, albeit not defended in any detail, by Hirst (1959), Austin (I962), and Pitcher (1970), amongst others. This is essentially the view that I recommend above and in my (manuscript-a). (As a referee points out, to defend this kind of view one may have to posit complex and rather arbitrary-looking psycho-physical relations. I reply to this worry in the aforementioned paper.)

${ }^{25}$ Whilst I endorse restrictive disjunctivist view that combines naïve realism about perception with a sense datum view of hallucination, one might be tempted to endorse an alternative view, one that e.g. combines naïve realism with an intentionalist view of hallucination (cf. Pautz: 20Io, manuscript). A referee has observed, however, that to endorse this type of view one might have to give up the on the naturalistic versions of intentionalism that philosophers Tye (1995) and Dretske (1995) have endorsed. This might well be correct (for reasons we need not get into here): but I am happy to give up on this reductive-physicalist project anyway. My own view is that naïve realists can only be non-reductive physicalists, holding the kind of view that Schaffer (20I7) endorses (cf. Moran manuscript-b).
} 
problem without saying anything about the mental nature of hallucinatory experience at all-and thus makes room for other factors to shape one's conception of the mental nature of such episodes. ${ }^{26}$

Accordingly, adopting my proposal has several significant advantages over other approaches. This provides good reason for naïve realists to see it as an important option for responding to the screening off problem that should be seriously considered. ${ }^{27}$

\section{References}

[I] Allen, Keith 2015. Hallucination And Imagination, Australasian Journal of Philosophy, 93/r: 287-302

[2] Audi, Paul 20r 2. A Clarification and Defense of the Notion of Grounding, in Metaphysical Grounding: Understanding the Structure of Reality, eds. Fabrice Correia and Benjamin Schnieder, Cambridge: Cambridge University Press: IO2-2I.

[3] Austin, J. L. 1962. Sense and Sensibilia, ed. Geoffrey Warnock, Oxford: Clarendon Press.

[4] Broad, Charlie 1962. Lectures On Psychical Research, London: Routledge and Kegan Paul.

[5] Burge, Tyler 2005. Disjunctivism and Perceptual Psychology, 33/I: I-78.

[6] Byrne, A. and Logue, H. (2008) 'Either/Or', in Disjunctivism: Perception, Action, Knowledge, A. Haddock and F. Macpherson (eds.), Oxford: Oxford University Press).

[7] Child, William 2004. Causality, Interpretation and the Mind, Oxford: Oxford University Press.

${ }^{26}$ I wish to mention one final advantage. This is that in rejecting premise (I) as I have suggested, we can reject Local Supervenience yet without having to claim just that it's merely a brute matter that the sort of experience involved in cases of hallucination cannot occur in cases of perception - thus avoiding positing mysterious, ungrounded necessities of the sort that Pautz (manuscript) worries about when discussing 'restrictive disjunctive intentionalism'. For on the present view, the fact that perceptual experiences cannot occur in hallucinatory cases and vice-versa is fully grounded in the essences of the relevant experience-types, which by their nature must be caused in certain ways. Thus, given certain plausible views regarding essence and necessity, the relevant necessities will be both grounded and unmysterious.

${ }^{27}$ Thanks to an audience at Warwick University, to whom an ancestor of this paper was presented; especially to Jack Shardlow for his comments on the paper presented on that occasion, and also to Ori Beck, Craig French, and Mark Kalderon. Likewise, thanks to participants at the New Directions Discussion Group at Cambridge University to whom a similar ancestor paper was presented. I would als like to specifically thank Ralf Bader, Tim Crane, Kati Farkas, Maarten Steenhagen, Paul Snowdon, and $\mathrm{Li} \mathrm{Li} \mathrm{Tan} \mathrm{for} \mathrm{their} \mathrm{helpful} \mathrm{comments} \mathrm{and} \mathrm{advice.} \mathrm{The} \mathrm{research} \mathrm{for} \mathrm{this} \mathrm{paper} \mathrm{was} \mathrm{completed} \mathrm{at} \mathrm{the} \mathrm{Uni-}$ versity of Cambridge, and was supported by an AHRC-Walker Studentship, hosted by the Faculty of Philosophy and Queens' College, as part of the AHRC Doctoral Training Partnership (grant no. AH/L 503897/I), and also by a Jacobsen Studentship and an Aristotelian Society Bursary. I would like to express my sincere thanks to these institutions and funding bodies for their support. 
[8] Crane, Tim 2005. What is the Problem of Perception? Synthesis Philosophica 20/40: 237-64.

[9] Crane, Tim 2006. 'Is There A Perceptual Relation? in Perceptual Experience, eds. Tamar Szabo Gendler and John Hawthorne, Oxford: Oxford University Press: $126-46$.

[io] Dancy, Jonathan I995. Arguments From Illusion, The Philosophical Quarterly, 45/I 8 I: 42 I- 38.

[I I] Dretske, Fred 1995. Naturalizing the Mind, MA: The MIT Press.

[I2] Farkas, Katilin 2006. Indiscriminability and the Sameness of Appearance', Proceedings of the Aristotelian Society, I06/2: 39- 59.

[13] Fish, William 2009. Perception, Hallucination, and Illusion, Oxford: Oxford University Press.

[14] Foster, John I986. Ayer, London: Routledge and Kegan Paul.

[15] Foster, John. The Nature of Perception, Oxford: Oxford University Press.

[16] French, Craig 2015. Review of Hallucination: Philosophy and Psychology, by Fiona Macpherson and Dimitris Platchias (eds.), Analysis 75/3: 528-30.

[17] Grice, Paul 196r. The Causal Theory of Perception, Proceedings of the Aristotelian Society (Supplementary Volume), 35/ I: I 2 I-52.

[18] Hawthorne, John and Kovakovich, Karson 2006. Disjunctivism, Aristotelian Society (Supplementary Volume), 80/I: I 45-83.

[19] Hellie, Benjamin 2013. The Multidisjunctive Conception of Hallucination, in Hallucination, eds. Fiona Macpherson and Dimitris Platchia MA: The MIT Press: I 49-74.

[20] Hinton, John Michael 1973. Experiences, Clarendon Press: Oxford.

[2I] Hirst, Rodney 1959. The Problems of Perception, London: George Allen \& Unwin.

[22] Johnston, Mark 2004. The Obscure Object of Hallucination, Philosophical Studies Vol. I 20/I-3: I I3-83.

[23] Lewis, D. I980. Veridical Hallucination and Prosthetic Vision, Australasian Journal of Philosophy 58/3: 239-49.

[24] Logue, Heather 201 3a. What Should the Naïve Realist Say About Total Hallucinations?' Philosophical Perspectives, 26/ I: I73-99.

[25] Logue, Heather 20I3b. Good News for the Disjunctivist About (one of) the Bad Cases, Philosophy and Phenomenological Research, 86/1: 105-33.

[26] Martin, Michael 1992. The Content of Experience, D. Phil Thesis, University of Oxford.

[27] Martin, Michael 1997. The Reality of Appearances, in Thought and Ontology, eds. Sainsbury, Mark. Milan: Franco Angeli: 8 I- 106.

[28] Martin, Michael 2004. The Limits of Self-Awareness, Philosophical Studies, I 20/I -3: 37-89.

[29] Martin, Michael 2006. On Being Alienated, in Perceptual Experience, eds. Tamar Szabo Gendler and John Hawthorne, Oxford: Oxford University Press: $355-407$.

[30] Martin, Michael 2013. Shibboleth: Some Comments on William Fish's Perception, Illusion and Hallucination' Philosophical Studies, I63/I: 37-48.

[3I] McDowell, John 20I3. Perceptual Experience: Both Relational and Contentful', 2I/I: I44-57. 
[32] Merricks, Trenton 200I. Varieties of Vagueness, Philosophy and Phenomenological Research 62/I I 45-I 57.

[33] Moran, Alex forthcoming-a. Naïve Realism, Seeing Stars, and Perceiving the Past, Pacific Philosophical Quarterly.

[34] Moran, Alex forthcoming-b. Kind-Dependent Grounding, Analytic Philosophy.

[35] Moran, Alex manuscript-a. Austinian Disjunctivism Defended, m.s. draft.

[36] Moran, Alex manuscript-b. Naïve Realism, Non-Reductive Physicalism and the Explanatory Gap, m.s. draft.

[37] Moran, Alex manuscript-c. Can the Epistemic Disjunctivist Avoid the Screening Off Problem?, m.s. draft.

[38] Nudds, Matt 2013. Naïve Realism and Hallucinations in Hallucination, eds. Fiona Macpherson and Dimitris Platchia MA: The MIT Press: I49—74.

[39] Pautz, Adam 20I0. Why Explain Visual Experience in Terms of Content? Perceiving the World, ed. Bence, Oxford: Oxford University Press: 254-309.

[40] Pautz, Adam 20I r. Can Disjunctivists Explain Our Access to the Sensible World?, Philosophical Issues, 2 I/I: 384-433.

[4I] Pautz, Adam manuscript. 'How Visual Experience Reaches to the World', m.s. draft.

[42] Pears, David. 1976. The Causal Conditions of Perception, Synthese, 33/I: $25-40$.

[43] Pitcher, George I971. A Theory of Perception, Princeton: Princeton University Press.

[44] Schaffer, Jonathan 20I7. The Ground Between the Gaps, Philosopher's Imprint, I $7 /$ I: I-I 6 .

[45] Schellenberg, Susanna 20II. Perceptual Content Defended, Nồs, 45/4: 7I4-50.

[46] Searle, John 20 I 5. Seeing Things As They Are: A Theory of Perception, Oxford: Oxford University Press.

[47] Siegel, S. 2004. Indiscriminability and the Phenomenal, Philosophical Studies, I 20: I/3: 37-89.

[48] Siegel, S. 2008. The Epistemic Conception of Hallucination, in Disjunctivism: Perception, Action, Knowledge, eds. MacPherson, Fiona and Haddock, Adrian. Oxford: Oxford University Press: 206-23.

[49] Smith, David 2002. The Problem of Perception, Harvard University Press.

[50] Smith, David 2008. 'Disjunctivism and Discriminability', in Disjunctivism: Perception, Action, Knowledge, eds. MacPherson, Fiona and Haddock, Adrian. Oxford: Oxford University Press: I 82-203.

[5I] Snowdon, Paul I98I. Perception, Vision and Causation, Proceedings of the Aristotelian Society, New Series, 8 I/I: I75-92.

[52] Snowdon, Paul 2005a. The Formulation of Disjunctivism: A Response to Fish, Proceedings of the Aristotelian Society, New Series, I05/I: I29-4I.

[53] Snowdon, Paul 2005b. Some Reflections on an Argument from Hallucination, Philosophical Topics, 33/1: 285-303.

[54] Soteriou, Matthew 2005. The Subjective View of Experience and its Objective Commitments, Proceedings of the Aristotelian Society, New Series, I 5/I: I77I90.

[55] Soteriou, Matthew 2013. Disjunctivism. Routledge. 
[56] Strawson, Peter Frederick 1979. Perception and its Objects, in Perception and Identity: Essays Presented to A.J. Ayer with His Replies, ed. Graham Macdonald London: Macmillan: 4I-6o.

[57] Sturgeon, Scott 2008. Disjunctivism About Visual Experience, in Disjunctivism: Perception, Action, Knowledge, eds. MacPherson, Fiona and Haddock, Adrian. Oxford: Oxford University Press: I I $3-43$.

[58] Thau, M. (2004) 'What is Disjunctivism?', Philosophical Studies, I 20 (I-3): 193-253.

[59] Tye, Michael 1995. Ten Problems of Consciousness: A Representational Theory of the Phenomenal Mind, MA: The MIT Press.

[6o] Tye, Michael 20I4. What is the Content of a Hallucinatory Experience? in Does Perception Have Content?, ed. Brogaard, B.Oxford University Press, pp. 292-308.

[6I] van Inwagen, Peter I990. Material Beings. London: Cornell University Press. 